\title{
Fungi of Biotechnological Interest in the Discoloration of Textile Effluents
}

\author{
Raphael LAS ${ }^{2}$, Romero MPBC ${ }^{*}$, Glenda HGMSP${ }^{1}$, Felype TB ${ }^{1}$, Raquel PB ${ }^{1}$, Ana Lucia FP ${ }^{1}$ and Marcia VS \\ ${ }^{1}$ Department of Morphology and Animal Physiology, Federal Rural University of Pernambuco, Brazil \\ ${ }^{2}$ Department of Biochemistry, Federal University of Pernambuco, Brazil \\ *Corresponding author: Romero Marcos Pedrosa Brandão-Costa, Department of Morphology and Animal Physiology, Federal Rural University of \\ Pernambuco - UFRPE, Brazil
}

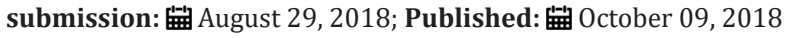

\begin{abstract}
The concern with the action of chemical dyes in human health is not only in Brazil, but throughout the world. One reason for the alert is due to recent results in European research related to the actions of dyes in baby foods, for example. However, the question of the risk of dyes has never been studied properly because of the assumption that these were harmless components. Several industries as pharmaceutical, cosmetic, printing and textile have widely used azo dyes. The textile industry is a substantial consumer of water and produces enormous volumes of contaminated water; the most important contaminants are azo dyes. The discharge of highly colored effluents affects water transparency, gas solubility in water bodies and may induce several human pathologies (carcinogenicity and toxicity). Therefore, new technologies using fungi to removal of such dyes before discharging them into environment is essential, mainly when related to human health.
\end{abstract}

Keywords: Bioremediation; Dye; Fungi; Medical research; Technology

\section{Introduction}

The textile industries are consuming large quantities of water that are returned to the environment, such as waste water. According to an estimate, around 40-65L of waste water is discharged per $\mathrm{kg}$ of fabric during the coloring process. This water contains a large amount of synthetic dyes with various residual concentrations in the effluent depending on the type of the dye molecules [1].

The azo dyes represent a major class of synthetic commercial dyes, showing a broad variety of structures and colors that represent up to $70 \%$ of the total textile dyes used [2]. Such dyes belong to the class of aromatic and/or heterocyclic compounds which are characterized by the presence of one or more azo $(-\mathrm{N}=\mathrm{N}-)$, and your degradation products are generally toxic and even carcinogenic to the aquatic organisms. Therefore, the effective removal of azo dyes from effluent prior to discharge into the environment is of extreme importance [3].

Many industries have been using conventional physicochemical methods for the treatment of waste water from the textile industry. These methods are not destructive, but they only transfer the contaminants from one form to another, thus generating a new different type of pollution problem [4]. In addition to being costly method and producing large amounts of Iodine after treatment [5].

Actually, the biological methods are seen as specific, of low energetic intensity, energy-efficient and environmentally safe as they result in partial or complete bioconversion of organic pollutants to stable and non-toxic final products. Many species of bacteria, fungi and algae have the ability to absorb and/or degrade azo dyes [6].

The application of filamentous fungi in the decolouration process is an attractive alternative due to its low cost and the possibility of total mineralization of the dye. Since such fungi are present in all environments, and the fast adaptation of their metabolism with various sources of carbon and nitrogen is important for their survival [7]. However, there are few studies on the decolorizing potential of filamentous fungi in regions of extreme conditions, such as the Caatinga biome, with the hypothesis that these microorganisms also develop adaptation mechanisms to survive adverse conditions, as well as the plants of that region. Thus, the objective of this work was to elaborate a literature review on an efficient decolouration of dyes from the textile industry by fungi isolated from the rhizosphere of the Caatinga biome as a proposal for a better application in public health.

\section{The textile industry}

In the industrial area, the textile sector stands out as one of the oldest in the world. The textile industry has grown considerably in recent decades and the sector is considered one of the industrial segments that occupies a prominent position in the economy of 
the most developed countries and is the flagship of development of many of the called emerging countries [8].

Currently, the Asia accounts for $73 \%$ of the total volumes produced in the world, most notably in order to: China, India, Pakistan, South Korea, Taiwan, Indonesia, Malaysia Thailand and Bangladesh, according to the Brazilian Industry Association Textiles. In Brazil, the textile market is not less important, having played a major role in the country's development process. Currently the Brazilian textile industry represents an extraordinary economicsocial value and the country occupies the fourth position among the world's largest producers of clothing and fifth among the largest producers of textile manufactures. In the national territory, there are about 5,000 textile industries, being 11\% large, 21\% small and $68 \%$ micro enterprises [9], distributed in the south region (Santa Catarina), southeast region (São Paulo and Minas Gerais) and northeast region (Pernambuco, Bahia and Ceará).

\section{Textile azo-dye}

Organic dyes and pigments can be defined as intensely colored substances which, when applied to a material, gives it color. Specifically, textile dyes are organic compounds whose purpose is to give a certain fiber (substrate) a certain color, under preestablished process conditions. They are also significant sources of aesthetic pollution and directly affect aquatic life [10].

It is estimated that more than 80,000 tons/year of dyes consumed in textile dyeing processes, which requires $70-150 \mathrm{dm}^{3}$ of water and $40 \mathrm{~g}$ of reactive dyes, per $\mathrm{kg}$ of cotton. The amount of water consumed and released varies depending on the types of fabrics used. Therefore, the compositions of the colored waste water vary with the type of fabric produced. The entry of these pollutants into water courses represents a serious ecotoxicological hazard and introduces the potential danger of bioaccumulation that may affect humans through the food chain [11].

Among all types of commercial synthetic dyes, azo dyes make up the largest class that exhibits a wide variety of colors and structures and accounts for up to $70 \%$ of the total textile dyes used [12]. They are a widely used in the textile industry, because of their stability, color variety and ease of application [13]. Azo dyes are aromatic compounds which containing azo groups $(-\mathrm{N}=\mathrm{N}-)$ and substituents (auxochromes) [14]. Azo dyes may be reduced to potentially carcinogenic aromatic amines in oxygen deficient conditions. This poses a threat to agriculture and to the health of people living in the surrounding areas [15].

\section{Textile dye toxicity}

The azo dyes present higher toxicity because the reducing medium presents itself as a favorable environment for the reductive cleavage of the aromatic rings and consequent formation of aromatic amines with carcinogenic and mutagenic potential [16]. It is estimated that, during the manufacture and application of these dyes, about 10 to $15 \%$ is released into the environment through mainly effluent discharges. Dyes based on benzene and amines may release these substances as metabolites, which are potentially carcinogenic. Studies with microorganisms and mammalian cells have shown that several of these substances have mutagenic and genotoxic activity [17].

These substances have a high persistence in aquatic environment because they present in their chemical composition a large number of aromatic rings, azo bonds, amines and sulphonyl groups. These characteristics give the dye-containing effluents a slow process of biodegradation, in addition, the residues of these compounds have a high toxic potential for the organisms exposed to them [18].

In 2005, in Brazil, CONAMA Resolution No. 357 was published, which establishes the conditions and standards for the release of industrial effluents, including the potential to cause toxic effects on the receiving body. Furthermore, Resolution No. 430 of CONAMA, published in May 2011, changes and complements Resolution No. 357 , establishing criteria for the collection of compliance with the parameters of toxicity by the state environmental agencies. As a result, these bodies are already requiring, through Ordinances and Resolutions, that companies comply with the established toxicity limits for effluents.

\section{Treatment of the textile industrial effluents}

The main cause of pollution involving textile industries is the durability of dye residues in waste water. Therefore, it is necessary to develop effective treatments and technologies for the decolouration of dyes in effluents [19]. There are many reports on the use of physicochemical methods for removing color from dyes. In recent decades, several physicochemical methods have been developed for the removal of dyes from textile effluent, but these methods are not suitable due to the production of large amounts of toxic iodine, aromatic amines, and residual secondary products, besides being costly methods. However, in the current scenario, biological treatment methods have been more appropriate and widely used because of their cost-benefit ratio, less sludge production capacity, and sustainable nature [20].

Bioremediation, or use of microbial techniques to deal with pollution, is a key of research in the environmental sciences. In this approach, microorganisms acclimate to toxic waste and new resistant strains develop naturally, which then transform various toxic chemicals into less harmful forms. Several biotechnological approaches have attracted interest in combating azo dye pollution in an eco-efficient way. Azo dyes are xenobiotic in nature and recalcitrant for biodegradation, and the microbial use or enzymatic treatment method for complete decolorization and degradation of such textile effluent dyes has the following advantages: (1) being sustainable, (2) having a minor cost, (3) production of less sludge, (4) obtaining final products that are non-toxic or have complete mineralization; and (5) which requires a lower consumption of water compared to physicochemical methods [21].

There are several reports on the drawbacks of using conventional physicochemical techniques and therefore remediation using microbes may play a central role. Microbial decolouration 
involving bacteria [22], yeasts and fungi [23]. Emerged as a selfsustaining approach. The effectiveness of microbial decolouration depends on the adaptability and activity of the microorganisms selected. Therefore, a large number of species have been tested for decolouration and mineralization of various dyes in recent years [24]. The isolation of potent species and thus their degradation is one of the interesting biological aspects of effluent treatment.

Microbiological decolouration can occur through biosorption, enzymatic degradation or a combination of both. The efficacy of bleaching techniques for the removal of azo dyes depends on the class of dye as well as their various substituent groups and the physic-chemical characteristics of the effluent such as $\mathrm{pH}$, temperature, salt content and the presence of organic pollutants [25].

\section{Decolouration of azo dyes using filamentous fungi}

The microorganisms are sensitive in the presence of chemical substances, such as dyes, high salinity, $\mathrm{pH}$ variation and high content of organic compounds [26]. For bioremediation processes, the most used microorganisms are the isolates from environments contaminated by the textile industry, including soil, effluents and sludge from waste water treatment plants because they are adapted to grow under extreme conditions [27].

The filamentous fungi are present in all environments, as well as rapid adaptation of your metabolism with various sources of carbon and nitrogen is important for your survival. The application of filamentous fungi in the decolouration process is an attractive alternative due to its low cost and the possibility of total mineralization of the dye [28]. The decolouration can be done by absorption or enzymatic degradation.

The adsorption capacity of the fungal biomass increases with temperature as a result of increased surface activity and kinetic energy of the dye [29]. However, the decolouration is decreased at very high temperatures, which is possibly due to deactivation of the surface of the absorbent or the destruction of some active sites. In addition, the dye's adsorption depends on the concentration of the dye; in higher concentrations, adsorption is decreased.

\section{Biotechnological potential of caatinga biome fungi}

The Caatinga is the only essentially Brazilian biome, presenting several endemic species. Currently, due to the high degradation of native areas, the caatinga represents a threatened natural heritage. Only between 2002 , and 2008, almost $16,600 \mathrm{~km}^{2}$ were deforested, which means a loss of more than $50 \%$ of the area, which affects the maintenance of the region's climate, the occurrence of rainfall, soil quality, desertification, animal and plant survival, and specially the quality of life.

In the semi-arid regions present in tropical countries, where a large part of the fungal diversity is present, the fungi usually have a high capacity of osmotic resistance and adaptability to specific conditions of $\mathrm{pH}$ and salinity, and thus fungi of these regions become promising targets of bioprospecting and besides this, they can develop adaptation mechanisms for possible application in bioremediation of areas contaminated by textile effluents and other recalcitrant substances.

\section{References}

1. Muhammad I (2015) Microbial biotechnology for decolorization of textile wastewaters. Reviews in Environmental Science and Bio/Technology 14(1): 73-92.

2. Weeranuch L (2013) Characterization of a new oxygen-insensitive azoreductase from Brevibacillus laterosporus TISTR1911: Toward dye decolorization using a packed-bed metal affinity reactor. Bioresource technol 150: 298-306.

3. Liang T (2013) Aerobic decolorization and degradation of azo dyes by growing cells of a newly isolated yeast Candida tropicalis TL-F1. Bioresource technology 138: 307-313.

4. Avinash AK (2011) Decolorization of adsorbed textile dyes by developed consortium of Pseudomonas sp. SUK1 and Aspergillus ochraceus NCIM1146 under solid state fermentation. J Hazard Mater 189(1-2): 486-494.

5. Ram-Lakhan S, Pradeep-Kumar S, Rajat-Pratap S (2015) Enzymatic decolorization and degradation of azo dyes-A review. International Biodeterioration \& Biodegradation 104: 21-31.

6. Razia K, Bhawana P, Fulekar MH (2013) Microbial decolorization and degradation of synthetic dyes: a review. Reviews in Environmental Science and Biotechnology 12(1): 75-97.

7. Myrna S (2012) Microbial decolouration of azo dyes: a review. Process Biochemistry 47(12): 1723-1748.

8. Amaral FM (2014) Color, organic matter and sulfate removal from textile effluents by anaerobic and aerobic processes. Bioresource technology 163: 364-369.

9. Tatoba WR (2011b) A sequential aerobic/microaerophilic decolorization of sulfonated mono azo dye golden yellow HER by microbial consortium GG-BL. International Biodeterioration \& Biodegradation 65(7): 1024-1034.

10. Dorian P, Francisco CJ, Germán B (2013) Azo dye decolorization assisted by chemical and biogenic sulfide. J Hazard Mater 250: 462-468.

11. Kshama B (2016) Exploring bioremediation strategies to enhance the mineralization of textile industrial wastewater through sequential anaerobic-microaerophilic process. International Biodeterioration \& Biodegradation 106: 97-105.

12. Samayita C (2013) Decolorization and biodegradation of congo red dye by a novel white rot fungus Alternaria alternata CMERI F6. Bioresource technology 147: 662-666.

13. Xuehui X (2016) Comparison of microbial community in hydrolysis acidification reactor depending on different structure dyes by Illumina MiSeq sequencing. International Biodeterioration \& Biodegradation 111: $14-21$

14. Maria J (2011) Sequential anaerobic-aerobic treatment of azo dyes: discoloration and amine degradability. Desalination 280(1): 339-346.

15. Ibrahim MB (1996) Microbial decolorization of textile-dye containing effluents: a review. Bioresource Technology 58(3): 217-227.

16. Pinheiro HM, Touraud E, Thomas $O$ (2004) Aromatic amines from azo dye reduction: status review with emphasis on direct UV spectrophtometric detection in textile industry wastewaters. Dyes and Pigments 61(2): 121-139.

17. Gottilieb A, Shaw C, Smith A, Wheatley A, Forsythe S (2003) The toxicity of textile reactive azo dyes after hydrolysis and discoloration. Journal of Biotechnology, Amsterdam 101(1): 49-56. 
18. Vivian V, Carlos-Renato C (2008) Decolorization of textile dye by candida albicans isolated from industrial effluents. J Ind microbiol Biotechnol 35(11): 1353-1357.

19. Sanjay GP (2014) Decolorization and degradation of xenobiotic azo dye reactive yellow-84A and textile effluent by Galactomyces geotrichum. Chemosphere 109: 234-238.

20. Rijuta GS (2011) Bacterial decolorization and degradation of azo dyes: a review. Journal of the Taiwan Institute of Chemical Engineers 42(1): 138-157.

21. Harpreet-Singh R (2005) Removal of dyes from the effluent of textile and dyestuff manufacturing industry: a review of emerging techniques with reference to biological treatment. Critical reviews in environmental science and technology 35(3): 219-238.

22. Tatoba RW, Mayur KB, Sanjay GP (2011a) Time dependent degradation of mixture of structurally different azo and non azo dyes by using Galactomycesgeotrichum MTCC 1360. International biodeterioration \& biodegradation 65(3): 479-486.

23. Mostafa T (2014) Azo and anthraquinone dye mixture decolourization at elevated temperature and concentration by a newly isolated thermophilic fungus, Thermo mucorindicae-seudaticae. Journal of Environmental Chemical Engineering 2(1): 415-423.
24. Pandey A, Singh P, Iyengar L (2007) Bacterial decolorization and degradation of azo dyes. International Biodeterioration \& Biodegradation 59: 73-84.

25. Bakshi DK (2006) Use of Phanerochaete chrysosporium biomass for the removal of textile dyes from a synthetic effluent. World Journal of Microbiology and Biotechnology 22(8): 835-839.

26. Mallavarapu M (2011) Bioremediation approaches for organic pollutants: a critical perspective. Environment International 37(8): 13621375.

27. Lamia A (2011) Decolorization and degradation of azo dye Methyl Red by an isolated Sphingomonas paucimobilis: biotoxicity and metabolites characterization. Desalination 274(1): 272-277.

28. Muhammad A (2008) Recent developments in biodegradation of industrial pollutants by white rot fungi and their enzyme system. Biodegradation 19(6): 771-783.

29. Emre E, Yasin K, Nurten-Kasikara P (2011) Biosorption kinetics of a direct azo dye Sirius Blue K-CFN by trametes versicolor. Electronic Journal of Biotechnology 14(2): 33.

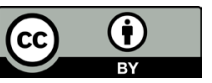

Creative Commons Attribution 4.0 International License

For possible submissions Click Here

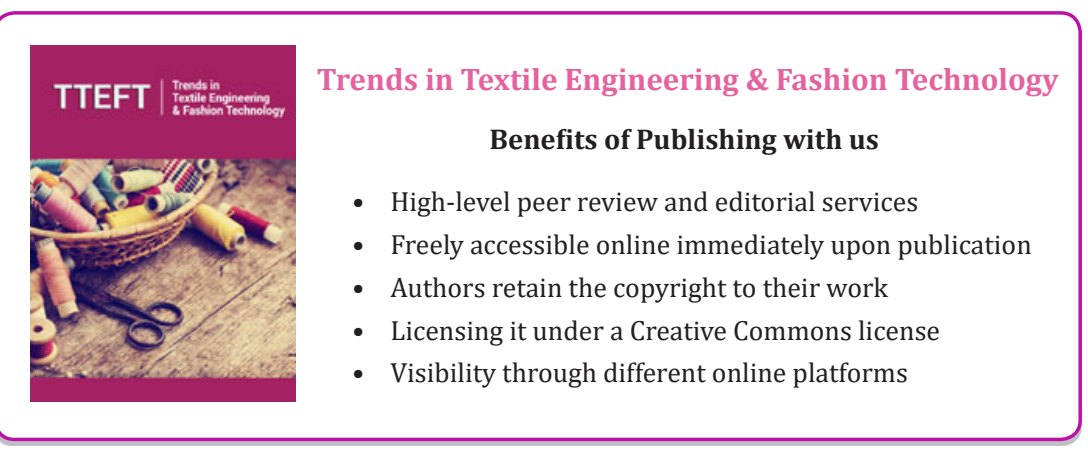

